\title{
INCUMPLIMIENTO DE LA BUENA ADMINISTRACIÓN DE JUSTICIA DEL TRIBUNAL CONSTITUCIONAL EN LA ADMISIÓN DEL RECURSO DE AMPARO. EL CASO ARRIBAS ANTÓN VS. ESPAÑA DEL TEDH \\ Breach by the Constitutional Court of the Fair Administration of Justice within the Admission Process of the Recurso de Amparo. The European Court of Human Rights Case Arribas Antón vs. Spain
}

\section{MARIO HERNÁNDEZ RAMOS \\ Universidad de Salamanca \\ mariohr@usal.es}

Cómo citar/Citation

Hernández Ramos, M. (2016)

Incumplimiento de la buena administración de justicia del Tribunal Constituciona en la admisión del recurso de amparo. El caso Arribas Antón vs. España del TEDH.

Revista Española de Derecho Constitucional, 108, 307-335 doi: http://dx.doi.org/10.18042/cepc/redc.108.10

\section{Resumen}

En el Asunto Arribas Antón vs. España, el Tribunal Europeo de Derechos Humanos no encuentra violación del art. 6.1. Convenio Europeo de Derechos Humanos ni del art. 13 Convenio Europeo de Derechos Humanos por parte de la Ley Orgánica 6/2007, de 24 de mayo que introduce el nuevo trámite de admisión del recurso de amparo, ni de la interpretación y aplicación llevada a cabo por el Tribunal Constitucional del requisito esencial de este nuevo trámite de admisión, la especial trascendencia constitucional. Sin embargo, sí realiza un apercibimiento velado al Tribunal 
Constitucional por no estar satisfaciendo el principio de buena administración de justicia en la aplicación de su propia doctrina constitucional, que se demuestra con un minucioso análisis de su jurisprudencia.

\title{
Palabras clave
}

Tribunal Constitucional; Tribunal Europeo de Derechos Humanos; admisión del recurso de amparo; especial trascendencia constitucional; buena administración de justicia.

\begin{abstract}
In the Case Arribas Antón vs. Spain, the ECtHR finds no violation of art. 6.1 ECHR nor of art. 13 ECHR by both the Organic Law 6/2007 that introduces the new admission process of the recurso de amparo, and the interpretation or the application by the Spanish Constitutional Court of the essential requirement «the special constitutional importance». However it makes a veiled warning to the Spanish Constitutional Court not to be satisfying the principle of fair administration of justice in the application of its own constitutional doctrine, which is demonstrated by a detailed analysis of its case law.
\end{abstract}

\section{Keywords}

Constitutitional Court; European Court of Human Rights; admission of recurso de amparo; special constitutional importance; fair administration of justice. 


\section{SUMARIO}

I. INTRODUCCIÓN. EL NUEVO TRÁMITE DE ADMISIÓN DEL RECURSO DE AMPARO CONSTITUCIONAL. II. EL CASO ARRIBAS ANTÓN VS. ESPAÑA Y LA DOCTRINA DEL TEDH APLICABLE AL CASO: 1. Las alegaciones de las partes. 2. El razonamiento del TEDH sobre el art. 6.1 CEDH y el art. $13 \mathrm{CEDH}$ : seguridad jurídica, fin legítimo, y proporcionalidad: 2.1. Sobre el nuevo trámite de admisión del recurso de amparo y su interpretación 2.2. Sobre la aplicación del nuevo trámite de admisión del recurso de amparo. III. VALORACIÓN DEL TRÁMITE DE ADMISIÓN DEL RECURSO DE AMPARO POR EL TEDH A LA LUZ DE LA JURISPRUDENCIA DEL TC: 1. Definición del contenido y alcance de la especial trascendencia constitucional: 1.1. Definición y alcance del aspecto procedimental: justificación de la especial trascendencia constitucional (art. 49.1 LOTC). Razonable conocimiento del recurrente en amparo de las exigencias procedimentales. 1.2. Definición y alcance del aspecto material [art. 50.1.b) LOTC]. Mejorable desarrollo del concepto de especial trascendencia constitucional. 2. Falta de explicitación de la especial trascendencia constitucional en los recursos declarados admisibles. Patente mala administración de justicia del TC. IV. A MODO DE CONCLUSIÓN. ACATAMIENTO DE LA DOCTRINA ARRIBAS ANTÓN VS. ESPAÑA. EL RECONOCIMIENTO DE LA BUENA ADMINISTRACIÓN DE JUSTICIA. BIBLIOGRAFÍA.

A instancias del Asunto Arribas Antón vs. España ${ }^{1}$, el Tribunal Europeo de Derechos Humanos (TEDH) se ha pronunciado sobre la compatibilidad con el Convenio Europeo de Derechos Humanos (CEDH) del nuevo trámite de admisión del recurso de amparo constitucional introducido por la Ley Orgánica 6/2007 de 24 de mayo, de Reforma de la Ley Orgánica del Tribunal Constitucional (LOTC) y de su interpretación y desarrollo realizado por el Tribunal Constitucional (TC). Arribas Antón vs. España encarna los miles de recursos de amparo que fueron inadmitidos a trámite sin ningún tipo de argumentación jurídica más que la cita del precepto que regula la inadmisión por el Alto Tribunal español tras la entrada en vigor el 26 de mayo de 2007. El problema sobre la no argumentación de las inadmisiones de los recursos de amparo, más allá del perjuicio práctico al recurrente, es un problema al que ya

1 Trabajo elaborado en el marco del proyecto «Gobernanza económica europea y transformación constitucional», financiado por el Ministerio de Economía y Competitividad, referencia DER2014-57116-P.

Caso Arribas Antón vs. España, núm. 16563/11, TEDH 20 de enero de 2015, en adelante, Caso Arribas Antón vs. España. 
se le ha dado respuesta y sobre el que hay una firme doctrina, tanto constitucional como del $\mathrm{TEDH}^{2}$.

Sin embargo, las deficiencias del señalado desarrollo jurisprudencial no se circunscribían a las inadmisiones, puesto que tampoco las admisiones de los recursos de amparo fueron argumentadas en su mayoría hasta la decisión del TEDH Arribas Antón vs. España, con lo que durante años se les privó a futuros recurrentes de una información muy importante para poder orientar sus eventuales demandas, además de la consiguiente falta de legitimación y control de esas concretas decisiones judiciales.

En consecuencia, el problema fundamental que el TEDH señaló al analizar este desarrollo jurisprudencial —y sobre el que se centrará este comentario- es que la ausencia de esta justificación supone el incumplimiento de una buena administración de justicia por parte del TC, que se traduce a su vez en una amenaza al principio de seguridad jurídica.

Este trabajo analiza, en primer lugar, los argumentos principales esgrimidos por el TEDH para determinar este incumplimiento de la buena administración de justicia del TC y la amenaza a la seguridad jurídica. En segundo lugar, trata de ilustrar la conclusión del TEDH de este incumplimiento y amenaza con una exposición exhaustiva de la jurisprudencia del TC sobre los principales aspectos del procedimiento de admisión del recurso de amparo. Por último, se justificará a través de la jurisprudencia constitucional que el Alto Tribunal español ha acatado la sentencia del TEDH y asumido sus indicaciones ${ }^{3}$.

\section{INTRODUCCIÓN. EL NUEVO TRÁMITE DE ADMISIÓN DEL RECURSO DE AMPARO CONSTITUCIONAL}

La introducción por la Ley Orgánica 6/2007, de 24 de mayo, de Reforma de la LOTC del actual trámite de admisión del recurso de amparo constitucional, largamente debatida ${ }^{4}$, fue motivada por una serie de causas en

2 No obstante, el escenario en el que se desarrolló esta problemática era novedoso, puesto que se inadmitieron miles de recursos de amparo antes de que el TC llevara a cabo una necesaria interpretación y desarrollo del proceso de admisión que orientara a los recurrentes.

3 Sobre otros retos que plantea este pronunciamiento del TEDH, vid. González y Ruiz (2015).

4 La bibliografía en este punto es muy extensa: Espín et al. (2006); Carrillo López (2008); Balaguer et al. (2008); Bustos Gisbert (1999); VV.AA. (1999) y Pérez Tremps (2008). 
las que no podemos detenernos aquís. Con la citada reforma se persiguió restaurar la posibilidad de que el TC volviera a dedicar suficiente tiempo y recursos para su función primordial y que los recursos de amparo no volvieran a colapsar la jurisdicción constitucional ${ }^{6}$. Este objetivo intentó abordarse principalmente a través de la reforma del trámite de admisión del recurso de amparo ${ }^{7}$.

Hasta la reforma operada por la Ley Orgánica 6/2007, en la fase de admisión el recurrente en amparo tan solo debía alegar la vulneración de un derecho fundamental. Tras la citada reforma, además de la mencionada alegación se exige como condición imprescindible que el recurrente satisfaga el requisito de justificar (art. 49.1 LOTC) la especial relevancia constitucional del recurso introducido por el art. 50.1.b) LOTC. Esto quiere decir que la mera alegación de una supuesta violación de un derecho fundamental no es suficiente para la admisión a trámite de un recurso de amparo.

Por tanto, este nuevo trámite de admisión pivota sobre dos elementos novedosos principales: uno de carácter procedimental, sobre la obligación que pesa sobre el recurrente de justificar la especial trascendencia constitucional del recurso (art. 49.1 LOTC) y otro de carácter material o sustantivo, como un requisito fundamental para la admisión a trámite del recurso [art. 50.1.b) LOTC] (Hernández Ramos, 2008: 45-57). Este segundo elemento enfatiza la función objetiva del recurso de amparo como criterio de admisión, postergando, solo en la fase de admisión, la función subjetiva (Pérez Tremps, 1994).

Ambos elementos necesitaban ser interpretados por el TC para una concreción de significado y contenido. Sin embargo, el TC tardó años en comenzar a clarificar este nuevo procedimiento y desarrollar estos conceptos. El comportamiento del TC tanto en la inadmisión como en la admisión de los recursos ha sido objeto de muchas críticas y finalmente del pronunciamiento Arribas Antón contra España del TEDH.

Hernández Ramos (2009: 21-51).

6 Exposición de Motivos de la Ley Orgánica 6/2007.

7 Por supuesto, ese no fue el único cambio introducido (Aragón Reyes [2009]; Fernández Farreres [2007]; Cabañas García [2010a: 48-52]). 


\section{EL CASO ARRIBAS ANTÓN VS. ESPAÑA Y LA DOCTRINA DEL TEDH APLICABLE AL CASO}

\section{LAS ALEGACIONES DE LAS PARTES}

El demandante, el señor Agustín Arribas Antón, tras un largo procedimiento contencioso-administrativo en el que se le acabó confirmando una sanción disciplinaria impuesta por el director del centro psiquiátrico donde trabajaba y a la que se oponía por falta de prueba de los hechos denunciados, vio inadmitido su recurso de amparo el 13 de septiembre de 2010 al no haber cumplido con la exigencia de demostrar la especial trascendencia constitucional. En consecuencia, el demandante se quejó ante el TEDH de la inadmisión de su recurso de amparo alegando que se había vulnerado su derecho de acceso a un tribunal (art. 6.1 CEDH) y argumentando que el motivo de inadmisión aducido por el TC fue en exceso formal [art. 49.1 y 50.1.b) LOTC] y que la interpretación del criterio de admisibilidad realizada por el TC fue contraria al CEDH, invocando los arts. 6.1 CEDH y $13 \mathrm{CEDH}$.

En esta demanda se sustancia en realidad si el nuevo modelo de trámite de admisión del recurso de amparo respeta las exigencias del CEDH, en concreto como apunta el TEDH, no la opción legislativa en sí, sino los efectos de esa elección legislativa, así como la interpretación de la nueva normativa realizada por el TC y la aplicación que él mismo lleva a cabo ${ }^{8}$. Los argumentos manejados por el demandante y por el Gobierno resumen las principales posturas que se han mantenido en contra y a favor de esta reforma.

El Gobierno, por su parte ${ }^{9}$, recordó que uno de los objetivos de la reforma había sido reforzar el papel de la jurisdicción ordinaria en la protección de los derechos fundamentales, enfatizando para enmarcar la discusión, que el recurso de amparo no es un recurso judicial que ni sustituye ni equivale a los recursos judiciales, sino que es un recurso subsidiario. Este mayor acento en el principio de subsidiariedad se debe al cambio de las condiciones de ejercicio de la jurisdicción constitucional que se ha dado desde el final de los años ochenta, cuando se realizaba una interpretación generosa y flexible de las modalidades de acceso al recurso, llegando a ser víctima de su éxito (VV.AA., 1999: 57-58; Sánchez Morón, 1987: 78-79), a la reforma de 2007 en la que el legislador constató que los jueces ordinarios cumplen con su función de garantes de los derechos fundamentales optando por destacar el carácter ex-

\footnotetext{
8 Caso Arribas Antón vs. España, $\$ 46$.

$9 \quad$ Ibidem, \$\$ 26-34
} 
traordinario del recurso de amparo reservándolo para los asuntos que ostenten una especial trascendencia constitucional, incumbiendo al recurrente alegar y demostrar el cumplimiento de este requisito. El Gobierno estimó que esta reforma constituía una «elección legítima en materia de protección de los derechos fundamentales» y que no privaba a los litigantes de su derecho a la tutela judicial efectiva ni al acceso a los tribunales. En el caso concreto, el recurrente obtuvo una respuesta motivada y no arbitraria a su demanda, pues tuvo la posibilidad de solicitar la tutela judicial del Tribunal de lo Contencioso-Administrativo y del Tribunal Superior de Justicia del País Vasco y, aunque el TC no se pronunciara sobre el fondo de su demanda, no afectó en nada a la adecuada protección de sus derechos. Además, matizó que en el momento en el que interpuso su recurso de amparo, el 9 de julio de 2010, el TC ya había publicado la Sentencia (STC) 155/2009, de 25 de junio en la que enunciaba los criterios a tener en cuenta para el examen de la especial trascendencia constitucional de un recurso. Por todo ello, el Gobierno concluyó que las condiciones de acceso al TC eran proporcionadas a la finalidad institucional perseguida por la reforma, esto es, "privilegiar la acción del poder judicial y reservar la jurisdicción constitucional a las causas en que las garantías de la Constitución y la autoridad de la jurisprudencia constitucional estén en juego». En consecuencia, no se vulneraría el art. 6.1 CEDH, como tampoco lo haría la obligación de demostrar la especial trascendencia constitucional por parte del recurrente probando la dimensión objetiva del recurso de amparo, deficiencia por la cual la demanda en amparo del recurrente fue inadmitida.

El demandante ${ }^{10}$, por su parte, cuestionó la evolución legislativa del procedimiento de amparo que ha acabado alterando su objeto principal, esto es, la tutela de los derechos fundamentales. Consideró que la acreditación de la vulneración de un derecho fundamental debería ser suficiente para proteger y garantizar el derecho en cuestión. En cambio, desde su punto de vista, la reforma realizada por la Ley Orgánica 6/2007 restringe la admisión a los recursos que ostenten una «trascendencia mediática, social o política mientras que otros asuntos que comporten vulneraciones reales y efectivas de derecho quedarían excluidos», habiendo optado el TC por la posibilidad de elegir libremente los asuntos a tratar para elaborar una jurisprudencia de los derechos fundamentales. En definitiva, el demandante sostuvo que su caso revestía de trascendencia constitucional tanto subjetiva como objetiva, que se esforzó en demostrarlo, y al ser inadmitido se le privó de su derecho de acceso al TC y en

10 Ibidem, $\$ \$ 35-40$. 
consecuencia del disfrute de los derechos de acceso a un tribunal (art. 6.1 $\mathrm{CEDH}$ ) y a un recurso efectivo (art. $13 \mathrm{CEDH}$ ).

\section{EL RAZONAMIENTO DEL TEDH SOBRE EL ART. 6.1 CEDH Y EL ART. 13 CEDH: SEGURIDAD JURÍDICA, FIN LEGIITIMO, Y PROPORCIONALIDAD}

Para determinar la no vulneración de los derechos de acceso a un tribunal (art. 6.1 CEDH) y a un recurso efectivo (art. 13 CEDH) del demandante, el TEDH centró sus reflexiones tanto en la regulación normativa del nuevo trámite de admisión del recurso de amparo (art. 49.1 LOTC y art. 50.1.b) LOTC) y su interpretación por el TC como en la aplicación de este nuevo procedimiento por parte del Alto Tribunal español. Para ello, el TEDH recurrió a tres categorías clásicas de su jurisprudencia: el principio de seguridad jurídica de las interpretaciones jurisprudenciales, el fin legítimo perseguido por la legislación nacional y el principio de proporcionalidad entre los medios implementados y la finalidad que se deseaba conseguir.

\subsection{Sobre el nuevo trámite de admisión del recurso de amparo y su interpretación}

El TEDH insistió en que su función no era sustituir a las autoridades nacionales competentes para definir la política más oportuna en materia de normativa de acceso a los recursos, sino valorar, desde la perspectiva del $\mathrm{CEDH}$, las decisiones dictadas en el ejercicio de su facultad de apreciación. No tiene competencia, por tanto, para controlar in abstracto ninguna ley, sino para averiguar si la manera en que han sido aplicadas al demandante ha infringido el CEDH. Por tanto, a pesar de que el TC haya declarado inadmisible un recurso de amparo alegando que no suscitaba ninguna cuestión con especial trascendencia constitucional o que el recurrente no haya demostrado la existencia de dicha trascendencia, el TEDH puede pronunciarse sobre la admisibilidad y el fondo de una demanda que se le plantee sobre el asunto ${ }^{11}$.

11 Ibidem, $\$ 51$. Como ejemplos de sentencias del TEDH en las que se pronuncia sobre el fondo del asunto a pesar de que el recurso de amparo hubiera sido inadmitido por el TC por carecer de especial trascendencia constitucional, vid. Caso Del Río Prada vs. España [GC], núm. 42750/09, TEDH 21 de octubre de 2013; Caso Varela Geis vs. España, núm. 61005/09, TEDH, 5 de marzo de 2013; Caso Manzanas Martín vs. España, núm. 17966/10, TEDH, 3 de abril de 2012; Caso R. M. S. vs. España, núm. 28775/12, TEDH, 18 de junio de 2013. 
Como punto de partida de su argumentación ${ }^{12}$, el TEDH afirmó que «el derecho a un tribunal», del que el derecho de acceso constituye un aspecto concreto, no es absoluto y tiene limitaciones, en particular en relación con los requisitos de admisibilidad de un recurso. La regulación de este derecho requiere de una normativa por parte del Estado que goza de cierto margen de apreciación ${ }^{13}$. Estas limitaciones no pueden restringir el acceso a un tribunal hasta vulnerar el derecho en su contenido esencial. Para determinar si esto sucede o no, el TEDH recordó el siguiente doble estándar: las limitaciones establecidas en la normativa nacional, por un lado, deben perseguir un fin legítimo; y, por otro, debe existir una relación razonable de proporcionalidad entre los medios empleados y el fin perseguido ${ }^{14}$.

En primer lugar, el TEDH estimó que el fin pretendido por el cambio legislativo de 2007 es legítimo, y aceptó la argumentación del Gobierno de que persigue mejorar el funcionamiento del TC y reforzar la protección de los derechos fundamentales para evitar una saturación excesiva de la función del TC para asuntos de menor importancia ${ }^{15}$.

En segundo lugar, el análisis de la relación razonable de proporcionalidad entre los medios empleados y el fin perseguido de las limitaciones de acceso al TC impuestas por los arts. 49.1. LOTC y 50.1.b) LOTC parte del reconocimiento por el TEDH de la «especificidad del papel que juega el TC como jurisdicción suprema de protección de los derechos fundamentales» ${ }^{16}$. En consecuencia, concedió que el procedimiento seguido ante el alto tribunal español «lleve aparejado un mayor formalismo». Por otra parte, no es desproporcionado o contrario al derecho de acceso al TC subordinar la admisibilidad de un recurso de amparo a la existencia de circunstancias objetivas como la especial trascendencia constitucional y a su justificación por parte del recurrente, puesto que estos criterios están establecidos en la LOTC e interpretados por la jurisprudencia constitucional. Además, también apreció que el TC

12 Caso Arribas Antón vs. España, $\$ 41$.

13 Caso García Manibardo vs. España, núm. 38695/97, TEDH, 29 de junio de 2000, $\$ 36$; Caso Edificaciones March Gallego S. A. vs. España, núm. 29028/95, TEDH, 19 de febrero de 1998, \$34; Caso Brualla Gómez de la Torre vs. España, núm. 26737/95, TEDH, 19 de diciembre de $1997 \$$ 33; Caso Mortier vs. Francia, núm. 42195/98, TEDH, 31 de julio de 2001, $\$ 33$.

14 Caso Ferre Gisbert vs. España, núm. 39590/05, TEDH, de 13 de octubre de 2009, $\$$ 27; Caso De la Fuente Ariza vs. España, núm. 3321/04, TEDH de 8 de noviembre de 2007, \$ 22; Caso García Manibardo vs. España, $\$$ 36; Caso Edificaciones March Gallego S. A. vs. Spain, $\$ 34$; Caso Brualla Gómez de la Torre vs. España $\$ 33$.

16 Ibidem, $\$ 49$. Vid. también Caso Ferré Gisbert vs. España, $\$ 39$. 
ha aplicado estos criterios de manera flexible, y que los criterios objetivos que el TC debe precisar y aplicar en su jurisprudencia ya estaban mencionados en la exposición de motivos de la Ley Orgánica 6/2007 que entró en vigor el 26 de mayo de 2007. Por último, el TEDH creyó importante señalar que en el presente caso el recurso de amparo ante el TC «era consecutivo al enjuiciamiento de la causa del demandante por parte de dos instancias judiciales» en las que pudo defenderse y obtuvo decisiones motivadas y no arbitrarias ${ }^{17}$.

\subsection{Sobre la aplicación del nuevo trámite de admisión del recurso de amparo}

Respecto de la aplicación que el TC está realizando del nuevo trámite de admisión y de su interpretación jurisprudencial, el TEDH partió de recordar que el art. 6.1 CEDH no obliga a crear jurisdicciones de apelación, casación y mucho menos competentes en materia de amparo ${ }^{18}$. Sin embargo, si en el Estado parte existen jurisdicciones de ese tipo, ha de asegurarse que los litigantes gocen de las garantías establecidas por el art. 6.1 CEDH. En consecuencia, el TEDH advirtió de que las particularidades de cada trámite jurisdiccional nacional pueden vulnerar el derecho de acceso a un tribunal si las formalidades para interponer un recurso o su interpretación impiden el examen sobre el fondo del recurso ejercitado por el interesado ${ }^{19}$. Por ello, el TEDH recomendó «tomar en cuenta el conjunto del proceso llevado a cabo en el orden jurídico interno y el papel desempeñado por el Tribunal Constitucional $»^{20}$. No obstante, en este punto y en consonancia con el mayor formalismo permitido en sede del TC, el TEDH hizo una importante puntualización: los requisitos de admisibilidad para un recurso de amparo pueden ser más rigurosos que para un recurso ordinario ${ }^{21}$.

17 Caso Arribas Antón vs. España, $\$ 50$.

18 Ibidem, $\$ 42$.

19 Caso Ferré Gisbert vs. España, $\mathbb{\$} 28$; Caso Běleš y otros vs. República Checa, núm. 47273/99, TEDH, 12 de noviembre de 2002, \$ 69; Caso Zvolský y Zvolská vs. Republica Checa, núm. 46129/99, TEDH, 12 de noviembre de 2001\$55.

20 Caso Arribas Antón vs. España, $\$ 42$.

21 Es la primera vez que el TEDH establece para el recurso de amparo que los requisitos de admisibilidad puedan ser más rigurosos que para un recurso ordinario. Sí se había pronunciado al respecto sobre el recurso de casación ante el Tribunal Supremo, como, por ejemplo, en Brualla Gómez de la Torre vs. España, $\$ 37$; respecto de otros recursos de casación en la misma línea véase, por ejemplo, Běleš y otros vs. República Checa, $\$$ 62; Caso Levages Prestations Services vs. Francia, núm. 21920/93, de 23 de octubre de 1996, $\$ 45$. 
Además, el TEDH insistió en que solo puede enjuiciar estos requisitos desde la posición que el CEDH y los Estados miembros le han concedido, por lo que no le incumbe valorar la procedencia de las elecciones de política jurisprudencial llevadas a cabo por las jurisdicciones internas, sino comprobar la conformidad con el CEDH de los efectos de dichas elecciones. No obstante, es inexcusable que la aplicación de las decisiones judiciales nacionales respete siempre el principio de seguridad jurídica ${ }^{22}$. Respecto del trámite de admisión del recurso de amparo, este respeto implica dos exigencias ${ }^{23}$.

La primera exigencia requiere del TC que defina el contenido y el alcance del criterio de especial trascendencia constitucional [art. 50.1.b) LOTC], que a juicio del TEDH ha realizado desde su entrada en vigor. En efecto, el TEDH afirmó sin matices que, en el momento de interponer el recurso de amparo, el demandante ya contaba con mucha información sobre el significado y alcance de la nueva normativa reguladora del trámite de admisión, en especial los AATC 188/2008, de 21 de julio, y 289/2008, de 22 de septiembre, sobre el art. 49.1 LOTC y la STC 155/2009, de 25 de junio, sobre el art. 50.1.b) LOTC, además de la exposición de motivos de la Ley Orgánica 6/2007, de 24 de mayo.

La segunda exigencia se centra en demandar que el TC debe explicitar la aplicación de la especial trascendencia constitucional en los asuntos declarados admisibles con el fin de garantizar una buena administración de la justicia. A juicio del TEDH, los interesados deben poder contar con que las decisiones tomadas a este respecto por el TC sean aplicadas ${ }^{24}$. A diferencia de otros asuntos en los que el no respeto por el principio de seguridad jurídica supuso una clara violación del art. 6.1 $\mathrm{CEDH}^{25}$, el TEDH en el presente caso no se pronunció expresamente sobre si el TC había respetado la seguridad jurídica,

22 Caso Arribas Antón vs. España, $\$ 46$.

23 Otros asuntos donde el TEDH se pronuncia sobre los efectos de la interpretación de normas procesales y establece como límite la seguridad jurídica, pero no abunda, en cambio, en los dos requisitos que sí expone en este caso: Ferre Gisbert vs. España, núm. 39590/05, \$ 26; Miragall Escolano y otros vs. España, núms. 38366/97, 38688/97, 40777/98, 40843/98, 41015/98, 41400/98, 41446/98, 41484/98, $41487 / 98$ y 41509/98, TEDH, 25 de enero de 2000, \$\$ 33 y 37 . Aunque no versa sobre la interpretación de normas procesales, sobre la violación del art. 6.1 CEDH por violación de la seguridad jurídica vid. también el Caso De la Fuente Ariza vs. España, principalmente $\$ 27$.

24 Caso Miragall Escolano y otros vs. España, $\$ 33$.

25 Caso Ferre Gisbert vs. España, \$33; Caso Miragall Escolano y otros vs. España, $\$ 37$; Caso De la Fuente Ariza vs. España, $₫ 27$. En contra, vid. Matia Portilla (2009: 360361). 
aunque sí sobre alguno de sus componentes, como se analizará en el siguiente epígrafe.

Por último, frente a las quejas del excesivo formalismo del TC alegadas por el demandante ${ }^{26}$, el TEDH se centró en clarificar que la inadmisión de un recurso de amparo sin ninguna motivación más que la mera invocación de la norma que regula el procedimiento no vulnera el derecho de acceso a un tribunal (art. 6.1 CEDH).

Así lo ha establecido en repetidas ocasiones respecto del modelo de tutela de derechos fundamentales por la justicia constitucional más similar al español: el alemán ${ }^{27}$. El TEDH recordó que ya había sentenciado en varias ocasiones ${ }^{28}$ en demandas planteadas contra Alemania que la inadmisión de una Verfassungsbeschwerde alegando únicamente la norma que regula esa inadmisión sin más motivación es compatible con el art. 6.1 CEDH siempre que los problemas que planteara no revistieran una trascendencia especial o si no tuvieran suficientes visos de prosperar ${ }^{29}$. Por ejemplo, en la decisión de inadmisión de Greenpeace E. V. y otros vs. Alemania ${ }^{30}$, los demandantes alegaron la violación del art. 6.1 CEDH porque el Bundesverfassungsgericht (BVerfG) no había argumentado la inadmisión de la Verfassungsbeschwerde. El TEDH insistió en su sólida doctrina de que los tribunales superiores de los Estados miembros, como el BVerfG, al inadmitir un recurso es suficiente con citar la norma que ampara esta negativa sin que sea necesario argumentarla, siempre y cuando no esté implicada una cuestión de importancia fundamental. En este caso se dio un problema añadido relacionado con la falta de motivación. A pesar de que la Bundesverfassungsgerichtsgesetz (BVerfGG) permite a las secciones inadmitir una Verfassungsbeschwerde [arts. 93.a) y 93.b) BVerfGG] y que no se fundamente la inadmisión [art. 93.d) BVerfGG], el BVerfG no citó en su inadmisión dicho art. 93.d) BVErfGG. El TEDH defendió la actuación del BVerfG y entendió que por el mero hecho de citar únicamente los arts. 93.a) y 93.b) BVerfGG y no el art. 93.d) BVerfGG no podía entenderse vulnerado

26 Sobre el debate de la inadmisión de recursos sin motivación a nivel nacional, tanto por el TC, como por el BVerfG, como por el Tribunal Supremo Federal de los Estados Unidos de América, vid. por todos Hernández Ramos (2009: 175-177).

27 Sobre Francia vid., por ejemplo, Burg and Others vs. France (dec.), núm. 34763/02, TEDH, 28 de enero de 2003.

28 Casos posteriores a la importante reforma de la Bundesverfassungsgerichtsgesetz de 1993, Ley de 2.8.1993, BGBl. I, 1442.

29 Caso Arribas Antón vs. España, $\$ 47$.

30 Greenpeace E.V. y otros vs. Alemania (dec.), núm. 18215/06, TEDH, 12 de mayo de 2009. 
el art. 6.1 CEDH, puesto que todos esos artículos están interrelacionados y «regulan el procedimiento de admisibilidad como un todo» ${ }^{31}$.

Respecto del alegado defecto de motivación en las decisiones de admisibilidad de recursos de amparo del TC, el TEDH especificó que ya ha sentenciado que «el rechazo de un recurso motivado por la sola referencia a la disposición de la aplicable al asunto» cumple con las exigencias del art. 6 CEDH y está desprovisto de arbitrariedad. ${ }^{32}$ En este sentido, el TEDH utilizó la misma argumentación que en las demandas contra Alemania ${ }^{33}$ y sentenció que "puede bastar que una jurisdicción superior rechace un recurso refiriéndose solamente a las disposiciones legales que prevén este procedimiento si las cuestiones planteadas en el recurso no revisten una importancia particular o no ofrecen suficiente posibilidad de éxito" ${ }^{34}$. Este razonamiento se aplica tanto a recursos de amparo inadmitidos con base en la legislación anterior a la reforma de $2007^{35}$ como a los actuales arts. 50.1.b) LOTC ${ }^{36}$ y 49.1. LOTC $^{37}$.

En consecuencia, el TEDH sentencia que al demandante no se le ha privado de la sustancia de su derecho de acceso a un tribunal; además, las limitaciones aplicadas perseguían un fin legítimo; por último, la aplicación de las limitaciones en cuestión no ha vulnerado el carácter razonable de la relación entre los medios empleados y el fin que se pretende. Por estas razones el TEDH estimó que el demandante no había sufrido ningún obstáculo desproporcionado en relación con su derecho de acceso a un tribunal garantizado por art. 6.1 $\mathrm{CEDH}^{38}$.

Respecto de la invocación del demandante de la violación de su derecho a un recurso efectivo (art. $13 \mathrm{CEDH}$ ) debido a la inadmisibilidad de su recurso de amparo, el TEDH señaló que esta queja está vinculada con la del

31 En John vs. Alemania (dec.), núm. 15073/03, TEDH, 13 de febrero de 2007, el TEDH sentenció la decisión con una lacónica afirmación: el BVerfG «no estaba obligado bajo la $\mathrm{CEDH}$ a dar razones por sus decisiones». De la misma manera, vid. Teuschler vs. Alemania (decisión), núm. 47636/99, TEDH, 4 de octubre de 2001 y Simon vs. Alemania (decisión), núm. 33681/96, TEDH, 6 de julio de 1999.

32 Caso Arribas Antón vs. España, $\$ 48$.

33 Caso Almenara Álvarez vs. España, núm. 16096/08, TEDH, 25 de octubre de 2011, $\$$ 27; Caso Varela Geis $c$. España (decisión), núm. 61005/09, TEDH, 20 de septiembre de 2011, $\$ 37$.

34 Varela Geis vs. España (decisión), $\$ 37$.

35 Por ejemplo, en Almenara Álvarez c. España, $\$ 27$.

36 Por ejemplo, en la Decisión Varela Geis vs. España, $\$ 38$.

37 Por ejemplo, en la Decisión Rupprecht vs. España, núm. 38471/10, TEDH, 19 de febrero de 2013, $\$ 17$.

38 Caso Arribas Antón vs. España, $\$ 52$. 
art. 6.1 $\mathrm{CEDH}^{39}$, pues los hechos aducidos por el demandante atañen a los mismos que los examinados desde la perspectiva del mencionado artículo y también debe ser inadmitida ${ }^{40}$.

\section{VALORACIÓN DEL TRÁMITE DE ADMISIÓN DEL RECURSO DE AMPARO POR EL TEDH A LA LUZ DE LA JURISPRUDENCIA DEL TC}

Como acabamos de comentar, el TEDH no apreció una vulneración de los derechos de acceso a un tribunal (art. 6.1 CEDH) o a un recurso (art. 13 $\mathrm{CEDH}$ ) por los efectos de la legislación que introduce el nuevo trámite de admisión del recurso de amparo [arts. 49.1 LOTC y 50.1.b) LOTC], pues, por un lado, persigue el fin legítimo de un mejor funcionamiento del TC y, por otro lado, no existe una desproporción entre los medios empleados y el fin perseguido al reconocer al recurso de amparo un mayor formalismo que permite subordinar su admisibilidad a la existencia de circunstancias objetivas como la especial trascendencia constitucional, contenidas en la LOTC e interpretadas por el TC.

Sin embargo, el TEDH destacó como un elemento imprescindible el hecho de que la aplicación de las decisiones judiciales nacionales respete siempre el principio de seguridad jurídica. Respecto del trámite de admisión del recurso de amparo este respeto implica dos exigencias. En primer lugar, el TC debe definir el contenido y el alcance del criterio de la especial trascendencia constitucional [art. 50.1.b) LOTC]. En segundo lugar, el TC debe explicitar la aplicación de la especial trascendencia constitucional en los asuntos declarados admisibles con el fin de garantizar una buena administración de justicia. A juicio del TEDH, los interesados han de poder contar con que las decisiones tomadas a este respecto por el TC sean aplicadas.

\section{DEFINICIÓN DEL CONTENIDO Y ALCANCE DE LA ESPECIAL TRASCENDENCIA CONSTITUCIONAL}

Un estudio riguroso de esta cuestión requiere separar la dimensión procedimental, esto es, el requisito de la justificación de la especial trascendencia constitucional, de la material o sustantiva, es decir, el significado en sí del concepto «especial trascendencia constitucional» ${ }^{41}$, puesto que el comporta-

\footnotetext{
39 González y Ruiz (2015: 167-175).

40 Caso Arribas Antón vs. España, \$\$ 53-57.

41 González Beilfuss (2016); Cabañas García (2010a: 53-69).
} 
miento del TC ha sido muy diferente para dar cumplimiento a la exigencia del principio de seguridad jurídica en el trámite de admisión del recurso de amparo respecto de ambas dimensiones, aunque finalmente el TEDH haya determinado su cumplimiento. Desde la entrada en vigor del nuevo trámite de admisión del recurso de amparo, el 26 de mayo de 2007 hasta que el TC comenzó a interpretarlo y desarrollarlo, pasó más de un año respecto del aspecto procedimental (ATC 188/2008, de 21 de julio) y dos años respecto del aspecto material (STC 155/2009, de 25 de junio). Durante ese tiempo miles de recurrentes plantearon sus demandas de amparo con una gran incertidumbre sobre su admisión a trámite.

\subsection{Definición y alcance del aspecto procedimental: justificación de la especial trascendencia constitucional (art. 49.1 LOTC). Razonable conocimiento del recurrente en amparo de las exigencias procedimentales}

La primera decisión con la que el TC arrojó luz sobre este nuevo trámite de admisión fue el Auto (ATC) 188/2008, de 21 de julio ${ }^{42}$. El TC interpretó que el recurrente ha de satisfacer necesariamente, de acuerdo con lo dispuesto en el art. 49.1 in fine LOTC, la carga de justificar en la demanda de amparo la especial trascendencia constitucional del recurso ${ }^{43}$. Esta carga se materializa en una serie de obligaciones que ya ha sido objeto de estudio por parte de la doctrina (Cabañas García, 2010a: 55-61; Matia Portilla, 2009, y Tirado Estrada, 2012).

En primer lugar, la obligación de justificar la especial trascendencia constitucional del recurso recae ahora sobre el recurrente en amparo. Si el recurrente no justifica argumentando explícitamente que la demanda de amparo ostenta una especial trascendencia constitucional, no será admitido a trámite ${ }^{44}$. En segundo lugar, esta obligación supone la disociación entre la vulneración de un derecho fundamental y la especial trascendencia constitucional del recurso ${ }^{45}$. Es decir, ya no es suficiente aludir a la violación de un derecho fundamental, sino que para la admisión es necesaria argumentar constitucionalmente ${ }^{46}$ sobre la

\footnotetext{
42 En contra de esta interpretación se pronuncia Garberí Llobregat (2009).

43 Vid. también AATC 188/2008, de 21 de julio; 289/2008 y 290/2008, de 22 de septiembre.

44 ATC 188/2008, de 21 de julio, FJ 1.

45 Ibidem, FJ 2.

46 A pesar de esta exigencia puede encontrarse excepciones, como la STC 118/2014, de 8 de julio [FJ 2.c)] en la que el TC pasa un poco por alto esta obligación no exigiendo un claro discurso justificativo.
} 
especial relevancia constitucional ${ }^{47}$, teniendo que contener cada demanda dos líneas argumentativas diferentes ${ }^{48}$. Por tanto, el TC exige una justificación formal (Cabañas García, 2012: 254-256) y no material, es decir, una justificación que no obligue al TC a suplir explicaciones o deducir de la argumentación del recurrente la especial trascendencia constitucional del recurso. En tercer lugar, no satisfacer esta carga es insubsanable, es decir, la inadmisión es irrecurrible excepto por el Ministerio Fiscal a través de un recurso de súplica ${ }^{49}$. Esta doctrina es bastante constante, aunque pueden encontrarse en la jurisprudencia del TC ejemplos contradictorios (Pérez Gurrea, 2012: 12-13).

Con el paso de los años estas tres notas se han ido consolidando en la jurisprudencia constitucional y la incertidumbre sobre el aspecto procedimental de la justificación de la especial trascendencia constitucional se ha ido atenuando; en la actualidad puede afirmarse que ha desaparecido. Sin ninguna duda, la manera de satisfacer esta exigencia está suficientemente explicada por el Alto Tribunal, pues ha ido arrojando paulatinamente luz sobre este elemento, hasta el punto de que ambas salas han compendiado todos los requisitos diseminados en su jurisprudencia desde la entrada en vigor de la Ley Orgánica 6/200750.

No obstante esta afirmación, hay que apuntar que el TC ha tomado decisiones contradictorias en esta materia, calificadas incluso de discrecionales por sectores de la doctrina (Urías Martínez, 2014: 88-90, 94) o de incoherentes por algún magistrado ${ }^{51}$. Aunque el TC se ha explicado respecto a esta problemática queriendo evitar un «excesivo formalismo» y aplicando "crite-

47 STC 155/2009, FJ 2; ATC 188/2008, FJ 3; ATC 289/2008, FJ 2 ; ATC 290/2008, FJ 2; ATC 80/2009, FJ 2; ATC 252/2009, FJ 1,

48 ATC 188/2008, FJ 2; STC 140/2013, de 8 de julio, FJ 4.a); STC 176/2012, FJ 3.

49 ATC 188/2008, de 21 de julio, FJ 3. Vid., por ejemplo, el ATC 108/2014, de 7 de abril.

50 Por ejemplo, STC 140/2013, de 8 de julio, FFJJ 3 y 4 (Sala Primera); STC 128/2014, de 21 de julio, FJ 2.c) (Sala Segunda).

51 Por ejemplo, en la STC 31/2013, de 11 de febrero, la Sala Segunda apreció una justificación material de la especial trascendencia constitucional del recurso (FJ 2). Sin embargo, esta debe ser de tipo formal, por lo que el magistrado Pérez Tremps denunció en su voto particular que con esta decisión el TC entraba en contradicción con su propia jurisprudencia, por ejemplo, con la STC 176/2012, de 15 de octubre. Otros ejemplos sobre la aceptación de la justificación material de la especial trascendencia constitucional: las sentencias (SSTTCC) 118/2014, de 8 de julio (FJ 2.c); 128/2014, de 21 de julio (FJ 2.c); 89/2014, de 9 de junio, FJ 2; 107/2012, de 21 de mayo, FJ 2. 
rios de flexibilidad $\aleph^{52}$, esta postura ha contribuido en ocasiones a la confusión y a los agravios comparativos ${ }^{53}$.

A pesar de todo ello, es claro que el recurrente tiene información suficiente en la jurisprudencia constitucional para redactar una demanda de amparo, esperar que el TC la aplique y así satisfacer los requisitos previstos.

\subsection{Definición y alcance del aspecto material [art. 50.1.b) LOTC]. Mejorable desarrollo del concepto de especial trascendencia constitucional}

La afirmación y conclusión anteriores no pueden predicarse del requisito de la especial trascendencia constitucional en su dimensión material, es decir, en lo que a su significado se refiere. Hasta que el TEDH dictó Arribas Antón $v s$. España, durante los siete primeros años en vigor del nuevo procedimiento de admisión, el recurrente no ha tenido certeza de en qué casos el TC podía apreciar que un recurso de amparo ostentara una especial trascendencia constitucional, a pesar de que el TEDH haya estimado suficiente los criterios contenidos en el art. 50.1.b) LOTC, las explicaciones de la Exposición de Motivos de la Ley Orgánica 6/2007, de 24 de mayo, y la STC 155/2009, de 25 de junio.

Esta incertidumbre se debe principalmente, a nuestro juicio, a tres causas. En primer lugar, el significado del concepto especial trascendencia constitucional dista mucho de ser un concepto claro, o de tener un contenido concreto (González Beilfuss, 2016; Ortega Gutiérrez, 2010) y que permita al recurrente acudir a la jurisdicción del TC con confianza de que su recurso tenga posibilidades de ser admitido a trámite. Requiere del desarrollo y de la explicación del TC a través de sus decisiones ${ }^{54}$. A pesar de ello, en segundo lugar, las inadmisiones no se publican, por lo que no se puede obtener información al respecto ${ }^{55}$. Y, en tercer lugar, el comportamiento del TC en la admisión del

52 STC 126/2014, de 21 de julio, FJ 2; ATC 28/2013, de 11 de febrero.

53 Un buen ejemplo de esto es el asunto inadmitido por el ATC 28/2013, de 11 de febrero, que motivó el voto particular del magistrado Valdés Dal-Ré.

54 Rodríguez-Piñero y Bravo Ferrer (2015) culpa al «excesivo rigor de la justificación en la demanda de la especial trascendencia constitucional del recurso de amparo».

55 A pesar de que la no motivación de las inadmisiones es un tema pacífico, incluso es sustentado por el TEDH como se ha explicado, sería muy útil que se pudiera obtener información al respecto. Sin embargo, hay que afirmar ni el mismo TC durante los primeros años tiene datos sobre la incidencia de la falta de relevancia constitucional en la inadmisión de los recursos (Morales Arroyo, 2014: 23). No obstante, parece que el TC ha empezado a ser consciente de la relevancia de esta información y en sus Memo- 
amparo es muy reprochable desde el punto de vista de las exigencias de la actuación jurisdiccional, pues la tónica general en sus decisiones hasta la decisión Arribas Antón vs. España ha sido la ausencia de argumentación por la que se admite a trámite el recurso, como se explicará más adelante.

Los tres criterios hermenéuticos de este concepto que detalla el art. 50.1.b) LOTC, y de inspiración claramente alemana, «especial trascendencia constitucional que se apreciará para la interpretación de la Constitución, para su aplicación o para su general eficacia, y para la determinación del contenido y alcance de los derechos fundamentales», se refieren, por un lado, a la importancia del recurso de amparo para posibilitar el desarrollo material de los derechos fundamentales u otras normas constitucionales ${ }^{56} ; y$, por otro lado, a la aplicación de la doctrina constitucional por parte de los poderes públicos en pos de la eficacia de los derechos fundamentales ${ }^{57}$.

La primera decisión que apuntó un motivo de admisión por su especial trascendencia constitucional fue la STC 70/2009, de 23 de marzo, que trataba de una cuestión en la que este «Tribunal no ha[bía] sentado doctrina». Sin embargo, es en la STC 155/2009, de 25 de junio, en la que el TC intenta desarrollar este concepto estableciendo supuestos en los que podría apreciar la especial trascendencia constitucional del recurso y en consecuencia ser admitido $^{58}$.

El TC enuncia en la STC 155/2009, FJ 2, una serie de siete supuestos en los que podría apreciar especial trascendencia constitucional en el recurso de amparo. El mismo TC advierte de que esta enumeración no es exhaustiva,

rias del 2014, por primera vez, da cuentas de los motivos de inadmisión de los recursos de amparo. Vid. el Cuatro núm. 15 de las Memorias del Tribunal Constitucional de 2014 http://www.tribunalconstitucional.es/es/tribunal/estadisticas/Paginas/Estadisticas2014.aspx

El primer y el tercer criterio hermenéutico del art. 50.1.b) LOTC se inspiran en la Grundsatzannhame, \$93a.1.a) BVerfGG. Para la relación entre ambos criterios véase Hernández Ramos (2009: 247-275).

57 El segundo criterio hermenéutico del art. 50.1.b) LOTC se inspira en la Durchsetzungannhame, $\$ 93$ a.1.a) BVerfGG). Para la relación entre ambos criterios vid. Hernández Ramos (2009: 276-290).

58 Durante los más de dos años entre la entrada en vigor de la Ley Orgánica 6/2007, de 24 de mayo y la STC 155/2009, de 25 de junio, el recurrente en amparo no tuvo información sobre el significado de este criterio de admisión, más que la Exposición de Motivos de la citada Ley Orgánica y el art. 50.1.b) LOTC. En ese período de tiempo el TC aplicó este requisito de inadmisión de manera más laxa, como ha apuntado en multitud de ocasiones (SSTTCC 143/2011, de 26 de septiembre, FJ 2; 176/2012, de 15 de octubre, FJ 3; 140/2013, de 8 de julio, FJ 4.d). 
pues sería contradictorio con el carácter dinámico de la jurisprudencia constitucional. Es indudable que esta enumeración de supuestos contenida en la STC 155/2009 ha sido de mucha utilidad para los recurrentes y ha arrojado mucha luz sobre el tema. Hasta la sentencia del TEDH Arribas Antón vs. España, el recurrente ha padecido cierta incertidumbre jurídica a la hora de enjuiciar si su pretensión satisfacía este requisito de admisibilidad, ya que, partiendo del análisis pormenorizado de la jurisprudencia constitucional, es difícil escudriñar el motivo por el cual el TC ha admitido a trámite el recurso en gran parte de las sentencias en amparo y, por tanto, difícil de configurar un contenido o de establecer criterios o cánones ${ }^{59}$. Esto se debe, obviamente, a que el Alto Tribunal no solía señalar expresamente, ni argumentar, la causa de admisión o el supuesto de la STC 155/2009 en el que podría encajar.

Estos siete supuestos, al igual que los tres criterios hermenéuticos del art. 50.1.b) LOTC pueden reconducirse también a los dos grupos señalados anteriormente. Por un lado, la admisión para el desarrollo material de los derechos fundamentales o normas constitucionales abarcaría los supuestos por nueva doctrina constitucional (supuesto a ${ }^{60}$ y por cambios en la doctrina constitucional (supuesto b) ${ }^{61}$. Por otro lado, la admisión para la aplicación por los poderes públicos y eficacia de los derechos fundamentales abarcaría los supuestos por «amparo» contra leyes y reglamentos (supuesto c) ${ }^{62}$, por reiterada jurisprudencia ordinaria vulneradora de un derecho fundamental (su-

59 No obstante, se han dado intentos por parte de la doctrina de identificar estos supuestos en las decisiones del TC. Vid., por ejemplo, González Alonso (2013); Esquivel Alonso (2013: 182-197); Sánchez de Ocaña Chamorro (2013: 139-141); Páez Mañá (2012: 527-543) y Hernández Ramos (2011).

60 Por ejemplo, SSTTCC 58/2010, de 4 de octubre; 15/2011, de 28 de febrero; 36/2001, de 28 de marzo; 37/2011, de 28 de marzo; 47/2011, de 12 de abril; 58/2011, de 3 de mayo de 2011; 125/2011, de 14 de julio; 114/2012, de 24 de mayo; 108/2012, de 21 de mayo; 96/2012, de 7 de mayo; 106/2012, de 21 de mayo; 97/2012, de 7 de mayo; 130/2012, de 18 de junio; 129/2012, de 18 de junio; 232/2012, de 13 de diciembre; 206/2012, de 12 de noviembre; 205/2012, de 12 de noviembre; 241/2012, de 17 de diciembre; 57/2013, de marzo; 7/2014, de 27 de enero; 9/2014, de 27 de enero, FJ 3; 176/2014, de 22 de octubre, FJ 2.

61 Por ejemplo, SSTTCC 38/2011, de 28 de marzo; 24/2011, de 24 de marzo; 67/2011, de 16 de mayo; 45/2011, de 11 de abril; 108/2011, de 20 de junio; 124/2011, de 14 de julio.

62 Por ejemplo, SSTTCC 90/2012, de 7 de mayo; 109/2012, de 21 de mayo; 127/2012, de 18 de junio; 156/2012, de 17 de septiembre; 55/2013, de 11 de marzo; 71/2013, de 8 de abril; 72/2013, de 8 de abril; 118/2014, de 8 de julio, FJ 2.c); 188/2014, de 17 de noviembre. 
puesto d); por incumplimiento de jurisprudencia constitucional e interés casacional (supuesto e ${ }^{63}$; por negativa manifiesta del deber de acatamiento de la doctrina del Tribunal Constitucional (supuesto $\mathrm{f})^{64}$. El último supuesto enunciado en el FJ 2 de la STC 155/2009, el supuesto g), constituye una cláusula de apertura y trasciende a los dos grupos: «cuestión jurídica de relevante y general repercusión social» ${ }^{65}$.

Tras un análisis exhaustivo de las sentencias del TC que no explicitan el motivo de admisión a trámite del recurso, se puede concluir que los supuestos de admisión para la aplicación de la doctrina constitucional por parte de los poderes públicos - y especialmente los órganos jurisdiccionales (Durchsetzungannhame) — son más difíciles de identificar en la jurisprudencia constitucional que los supuestos para llevar a cabo un desarrollo material de los derechos fundamentales o de las normas constitucionales (Grundsatzannahme). Por ello, la mayor incertidumbre a la que se enfrenta un recurrente es tratar de argumentar que su recurso de amparo debería ser admitido a trámite porque ostenta especial trascendencia constitucional para la aplicación de la doctrina constitucional en pos de la eficacia de los derechos fundamentales (Durchsetzungannhame), con la excepción de si se trata del supuesto c) que es fácilmente identificable. También es sencillo argumentar para su admisión los amparos con objeto en la negativa manifiesta del deber de acatamiento de la doctrina del TC (supuesto f). Esta negativa ha de tener un elemento intencional y volitivo por parte del tribunal $a q u o^{66}$. A pesar de la aparente sencillez de este supuesto, incluso algunos miembros del TC han expresado la necesidad de que sea desarrollado más en profundidad ${ }^{67}$. Sin embargo, el supuesto e), «cuando la doctrina del TC sobre el derecho fundamental que se alega en el recurso esté siendo incumplida de modo general y reiterado por la jurisdicción ordinaria», es complejo de argumentar e identificar a pesar de que se puede

63 Por ejemplo, SSTTCC 97/2010, de 15 de noviembre; 140/2010, de 21 de diciembre; 141/2010, de 21 de diciembre; 142/2010, de 21 de diciembre; 143/2010, de 21 de diciembre; 95/2012, de 7 de mayo; 119/2012, de 4 de junio; 149/2913, de 9 de septiembre.

64 Por ejemplo, SSTTCC 59/2010, de 4 de octubre; 95/2010, de 15 de noviembre; 59/2011, de 3 de mayo; 133/2011, de 18 de julio.

65 Por ejemplo, SSTTCC 96/2010, de 15 de noviembre; 29/2011, de 14 de marzo; 27/2011, de 14 de marzo; 57/2011, de 3 de mayo; 60/2011, de 5 de mayo; 61/2011, de 5 de mayo; 62/2011, de 5 de mayo; 125/2011, de 14 de julio, 124/2011 de 14 de julio; 123/2011, de 14 de julio; 138/2012, de 20 de junio; 118/2012, de 4 de junio.

66 ATC 26/2012, de 31 de enero FJ 3.

67 Voto particular de la magistrada Roca Trías en la STC 11/2014, de 27 de enero. 
intuir que es uno de los supuestos más presentes en las admisiones a trámite. A pesar de ello, el TC apenas lo señala ${ }^{68}$.

A pesar de que a partir de un análisis exhaustivo de la jurisprudencia constitucional puedan intuirse ciertas conclusiones, como que el Alto Tribunal concede mucha importancia a asuntos penales y de ámbito penitenciario, sobre cómputo de condena, sobre legalidad penal (art. 25.1 CE), sobre detenciones y habeas corpus (art. $17 \mathrm{CE}$ ), y sobre los que no exista doctrina constitucional o le den la oportunidad de desarrollar, reflexionar o cambiar su doctrina [supuestos a) y b) de la STC 155/2009, FJ 2], no cabe duda de que la definición del concepto y ámbito de aplicación de la especial trascendencia constitucional es patentemente mejorable por parte del TC.

\section{FALTA DE EXPLICITACIÓN DE LA ESPECIAL TRASCENDENCIA CONSTITUCIONAL EN LOS RECURSOS DECLARADOS ADMISIBLES. PATENTE MALA ADMINISTRACIÓN DE JUSTICIA DEL TC}

El segundo estándar que establece el TEDH para determinar el respeto del principio de seguridad jurídica es que el TC debe explicitar la aplicación de la especial trascendencia constitucional en los asuntos declarados admisibles con el fin de garantizar una buena administración de justicia. A juicio del TEDH, los interesados deben poder contar con que las decisiones tomadas a este respecto por el TC sean aplicadas. Del análisis de la jurisprudencia del TC tras la entrada en vigor de la Ley Orgánica 6/2007, y hasta la Sentencia Arri-

68 Son muchos los casos en los que se puede deducir de las varias sentencias del TC que se está realizando un «incumplimiento general y reiterado» de la jurisprudencia constitucional por parte de la jurisdicción ordinaria, como la práctica de la prueba en apelación de los principios de inmediación y contradicción de la prueba (SSTTCC $120 / 2013,119 / 2013,118 / 2013$, de 20 de mayo, en cierto modo también STC 157/2013, de 23 de septiembre); la falta de constitución de un depósito para plantear un recurso (STC 73/2013, de 8 de abril; STC 74/2013, de 8 de abril; SSTTCC 129/2012 y 130/2012, de 18 de junio; STC 154/2012, de 16 de julio); o multas de aparcamiento de la ORA en Madrid (TC 30/2013, de 11 de febrero, y STC 45/2013, de 25 de febrero). Sin embargo, en muchos recursos de amparo admitidos a trámite, es difícil reconocer las notas de generalidad y reiteración que creemos que caracterizan este supuesto. La ausencia de estas notas en el incumplimiento de la doctrina constitucional, en nuestra opinión, contribuiría a acercar este supuesto a la tutela subjetiva del derecho fundamental vulnerado, pues la mera vulneración de la jurisprudencia constitucional, puntual y anecdótica, no debería gozar, desde nuestro punto de vista, de especial trascendencia constitucional. Un ejemplo de esto podría encontrarse en la STC 121/2013, de 20 de mayo, FJ 5. 
bas Antón contra España, la explicitación de los motivos por los que el Alto Tribunal estima que un recurso de amparo ostenta especial trascendencia constitucional y, por tanto, es admitido a trámite fue absolutamente deficiente.

Los datos son concluyentes por sí mismos. En el año 2011, el TC explicitó la especial transcendencia constitucional en 4 ocasiones $^{69}$ de 102 sentencias dictadas en amparo (3,92\%); en 2012, en 6 ocasiones $^{70}$ de 124 sentencias (4,03\%); en 2013 de las 87 sentencias en amparo dictadas, solo en $23^{71}$ explicitó el motivo de la admisión ${ }^{72}$ (26,43 \%); en 2014 de las 109 sentencias en amparo el TC explicitó el motivo de la admisión en 15 sentencias $^{73}$ (13,76\%). En definitiva, teniendo en cuenta todas las sentencias apuntadas de 2011, 2012, 2013 y 2014, la media de razonamiento o explicitación de la especial trascendencia constitucional en este período de tiempo ha sido del $11,37 \%$.

69 SSTTCC 17/2011, de 18 de febrero, FJ 2; 68/2011, de 16 de mayo, FJ 3; 133/2011, de 18 de julio, FJ 3; 26/2011, de 14 de marzo, FJ 2.

70 SSTTCC 105/2012, de 11 de mayo, FJ 3; 107/2012, de 21 de mayo, FJ 2; 141/2012, de 2 de junio, FJ 2; 145/2012, de 2 de julio, FJ 2; 192/2012, de 28 de octubre, FJ 2.

71 SSTTCC 27/2013, de 11 de febrero, FJ 2; 75/2013, de 8 de abril, FJ 2; 115/2013, de 9 de mayo, FJ 3; 122/2013, de 20 de mayo, FJ 2; 126/2013, de 9 de mayo, FJ 2.c); 147/2013, de 6 de agosto FJ 2; 170/2013, de 7 de octubre, FJ 2c); 173/2013, de 10 de octubre, FJ 2; 216/2013, de 19 de diciembre, FJ 2 e); 55/2013, de 20 de mayo (no explicitado, pero es obvio que se trata del supuesto c); 77/2013, de 8 de abril, FJ 2; 116/2013, de 20 de mayo, FJ 3; 1/2013, de 11 de febrero, FJ 3; 2/2013, de 14 de febrero, FJ 3; 32/2013, de 11 de enero, FJ 2; 56/2013, de 11 de marzo, FJ 1.b); 127/2013, de 3 de junio, FJ 2; 191/2013, de 18 de noviembre FJ 2; 31/2013, de 11 de febrero, FJ 2; 44/2013, de 25 de febrero, FJ 2; 79/2013, de 8 de abril FJ 2; 125/2013, de 23 de mayo, FJ 3; 167/2013, de 7 de octubre, FJ 3.

72 A estas 23 hay que añadirle otros 4 decisiones en las que el TC argumenta la especial trascendencia constitucional, pero sin corresponder con alguno de los supuestos de la STC 155/2009: STC 76/2013, FJ 3, en la que reitera doctrina constitucional; STC 211/2013, de 16 de diciembre, FJ 4: «en el caso de autos estamos ante la desatención por parte del órgano judicial del ejercicio de la función jurisdiccional que comprende, entre otros extremos, la interpretación del fallo en la ejecución de las Sentencias»; STC 121/2013, de 20 de mayo, FJ 5; STC 212/2013, de 16 de diciembre, FJ 2.

SSTTCC 29/2014, de 24 de febrero, FJ 3; 46/2014, de 7 de abril, FJ 2.a); 47/2014, de 7 de abril, FJ 2.a); 79/2014, de 28 de mayo, FJ 3; 126/2014, de 21 de julio, FJ 2; 58/2014, de 5 de mayo, FJ 2; 79/2014, de 28 de mayo, FJ 3; 89/2014, de 9 de junio, FJ 2; 99/2014, de 23 de junio, FJ 2; 128/2014, de 21 de julio, FJ 2.c); 21/2014, de 10 de febrero, FJ 2; 32/2014, de 24 de febrero, FJ 2; 204/2014, de 15 de diciembre, FJ 2.b); 200/2014, de 15 de diciembre, FJ 2; 195/2014, de 1 de diciembre, FJ 2; 201/2014, de 15 de diciembre, FJ 2. 
Además de estas cifras, la actitud del TC ante la posibilidad de argumentar o explicitar los motivos de admisión, hasta la decisión de Arribas Antón vs. España no siempre fue la más positiva ${ }^{74}$. A veces ha expuesto o citado el argumento sobre la especial trascendencia constitucional del recurrente, pero no se ha pronunciado sobre si lo admite por ese motivo o no ${ }^{75}$. Una de las razones aducidas por los magistrados constitucionales para no señalar un supuesto concreto fue no constreñir sus decisiones a supuestos tasados como los que establece la STC 155/2009, FJ $2^{76}$. Sin embargo, no puede aceptarse, como se ha señalado a veces, que la especial trascendencia constitucional se trata «exclusivamente, de la voluntad del propio TC de pronunciarse sobre un asunto", y que "quizás no sea necesaria» la explicitación de la especial trascendencia constitucional de los asuntos admitidos a trámite (Urías Martínez, 2014: 86, $87,90)$. Desde el punto de vista de la actuación de un órgano jurisdiccional como es el TC, las cifras señaladas son absolutamente insuficientes, y debieron explicitarse y argumentarse los motivos de admisión de las demandas de amparo, pues contribuye a la seguridad, certidumbre o previsibilidad jurídica e información de los recurrentes, así como a la legitimación del TC y control de su actuación. Esta postura del TC contrasta frontalmente con la de su homólogo alemán, puesto que el BVerfG sí que explica o explicita con carácter general la razón de la admisión a trámite de las Verfassungsberscherden ${ }^{77}$.

Del estudio exhaustivo de la jurisprudencia constitucional, hasta la decisión Arribas Antón vs. España, se puede concluir que los supuestos de admisión más explicitados fueron los más fáciles de identificar, a saber, sobre los que no existía doctrina constitucional [supuesto a)] en 20 ocasiones $^{78}$, los que

74 Vid., por ejemplo, la STC 212/2013, de 16 de diciembre; por el contrario, vid. el ATC 108/2014, de 7 de abril.

75 SSTTCC 127/2013, de 3 de junio, FJ 2; 7/2014, de 27 de enero, FJ 2; 54/2014, de 10 de abril, FJ 2; 118/2014, de 8 de julio, FJ 2.

76 Decisiones en las que el TC ha señalado la especial trascendencia constitucional, pero sin encajarlas en ninguno de los supuestos de la STC 155/2009, FJ 2: SSTTCC 211/2013, de 16 de diciembre, FJ 4; 121/2013, de 20 de mayo, FJ 5; 212/2013, de 16 de diciembre, FJ 2; la 76/2013, de 8 de abril FJ 3, es admitida a trámite para reiterar la doctrina constitucional, como ya demandara Cabañas García (2010: 68-69).

77 Vid., por ejemplo, 2 BvR 2055/14, Sentencia del 15 de enero de 2015, $\$ 12$; 1 BvR 665/14, Sentencia de 20 de enero de 2015, $\$ 18$; BvR 1856/13, Sentencia de 21 de enero de 2015, $\$$ 8; 2 BvR 2049/13, 2 BvR 2445/14, Sentencia de 21 de enero de $2015, \$ 22$.

78 SSTTCC 17/2011, de 18 de febrero, FJ 2; 68/2011, de 16 de mayo, FJ 3; 133/2011, de 18 de julio, FJ 3; 105/2012, de 11 de mayo; FJ 5; 107/2012, de 21 de mayo, FJ 2; 141/2012, de 2 de junio, FJ 2; 145/2012, de 2 de julio, FJ 2; 192/2012, de 28 de 
daban al TC la oportunidad de desarrollar, reflexionar o cambiar su doctrina [supuesto b)] en 7 ocasiones $^{79}$, los que contenían una cuestión jurídica de relevante y general repercusión social [supuesto g)] en 6 ocasiones $^{80}$, y estos supuestos juntos en una misma sentencia, como supuestos a) y b) en una ocasión $^{81}$, y a) yg) en 5 ocasiones $^{82}$. A excepción de los amparos admitidos por violación de una ley o disposición general, supuesto c), explicitado 5 veces $^{83}$, los supuestos para garantizar la eficacia de los derechos fundamentales por los poderes públicos fueron menos explicitados. Por ejemplo, el TC nunca ha identificado el supuesto por reiterada jurisprudencia ordinaria vulneradora de un derecho fundamental [supuesto d) ${ }^{84}$. El incumplimiento de jurisprudencia constitucional e interés casacional [supuesto e)] fue señalado en 3 ocasiones ${ }^{85}$ y la negativa manifiesta del deber de acatamiento de la doctrina del TC [supuesto f)] fue explicitada en 3 ocasiones $^{86}$. Por último, en una sentencia el TC explicitó los supuestos c) y d) ${ }^{87}$ y en otra los supuestos e) y f) ${ }^{88}$.

octubre, FJ 2; 27/2013, de 11 de febrero, FJ 2; 75/2013, de 8 de abril, FJ 2; 115/2013, de 9 de mayo, FJ 3; 122/2013, de 20 de mayo, FJ 2; 126/2013, de 9 de mayo, FJ 2.c); 147/2013, de 6 de agosto FJ 2; 170/2013, de 7 de octubre, FJ 2c); 173/2013, de 10 de octubre, FJ 2; 216/2013, de 19 de diciembre, FJ 2e); 29/2014, de 24 de febrero, FJ 3; 46/2014, de abril, FJ 2.a); 47/2014, de abril, FJ 2.a); 79/2014, de 28 de mayo, FJ 3; 126/2014, de 21 de julio, FJ 2.

79 SSTTCC 26/2011, de 14 de marzo, FJ 2; 105/2012, de 11 de mayo, FJ 3; 58/2014, de 5 de mayo, FJ 2; 79/2014, de 28 de mayo, FJ 3; 89/2014, de 9 de junio, FJ 2; 99/2014, de 23 de junio, FJ 2; 21/2015, de 16 de febrero, FJ 2.

80 SSTTCC 56/2013, de 11 de marzo, FJ 1.b); 127/2013, de 3 de junio, FJ 2; 191/2013, de 18 de noviembre FJ 2; 200/2014, de 15 de diciembre, FJ 2; 201/2014, de 15 de diciembre, FJ 2; 1/2015, de 19 de enero, FJ 2. Los amparos parlamentarios, por norma general, suelen ser admitidos a trámite porque no tienen más instancias para tutelar sus derechos fundamentales. No obstante esta afirmación, algunas demandas de este tipo han sido inadmitidas. Véase, por ejemplo, el ATC 46/2011, de 28 de abril. STC 105/2012, de 11 de mayo, FJ 3.

SSTTCC 192/2012, de 29 de octubre FJ 2; 31/2013, de 11 de febrero, FJ 2; 44/2013, de 25 de febrero FJ 2; 79/2013, de 8 de abril FJ 2; 125/2013, de 23 de mayo, FJ 3. SSTTCC 55/2013, de 20 de mayo; 77/2013, de 8 de abril, FJ 2; 116/2013, de 20 de mayo, FJ 3; 128/2014, de 21 de julio, FJ 2.c); 1/2015, de 19 de enero.

Sí lo ha hecho posteriormente a la sentencia Arribas Antón c. España en una única ocasión: STC 133/2016, de 18 de julio, FJ 2.

SSTTCC 21/2014, de 10 de febrero, FJ 2; 32/2014, de 24 de febrero, FJ 2; 204/2014, de 15 de diciembre, FJ 2.b).

SSTTCC 2/2013, de 14 de febrero, FJ 4; 32/2013, de 11 de enero, FJ 2.

STC 167/2013, de 7 de octubre, FJ 3.

STC 195/2014, de 1 de diciembre, FJ 2. 
Las cifras expuestas permiten afirmar que el comportamiento del TC ha sido un ejemplo de mala administración de justicia en cuanto al trámite de admisión del recurso de amparo, y ha dejado en entredicho un disfrute pleno del principio de seguridad jurídica por parte de los recurrentes que ha corroborado el TEDH en la imprescindible decisión Arribas Antón vs. España.

\section{A MODO DE CONCLUSIÓN. ACATAMIENTO DE LA DOCTRINA ARRIBAS ANTÓN VS. ESPAÑA. EL RECONOCIMIENTO DE LA BUENA ADMINISTRACIÓN DE JUSTICIA}

La primera decisión del TC dictada tras la decisión del TEDH Arribas Antón vs. España de 20 de enero de 2015 fue la STC 9/2015, de 2 de febrero, en la que recoge la advertencia del TEDH argumentando que "constituye una exigencia de certeza que este Tribunal explicite el cumplimiento de este requisito (la especial trascendencia constitucional), haciendo así recognoscibles los criterios de aplicación empleados al respecto por el TC» (FJ 3).

A partir de esta decisión, y tras un análisis de la jurisprudencia de los primeros meses del $\mathrm{TC}^{89}$ hemos constatado que el TC ha acatado esta doctrina y explicita y motiva, por norma general ${ }^{90}$, la admisión de cada recurso de amparo, unas veces en los Antecedentes y otras en los Fundamentos Jurídicos. ${ }^{91}$ De esta manera, la explicitación de los motivos permite sacar conclusiones definitivas, y no meras conjeturas como las apuntadas en el epígrafe anterior sobre los supuestos en los que el TC más a menudo aprecia especial trascendencia constitucional. Los supuestos que más suele admitir el TC son aquellos

89 En el presente trabajo se han analizado las sentencias publicadas en la web del TC hasta el 2 de octubre de 2016.

90 No motivó la admisión en las siguientes SSTTCC 78/2015, de 30 de abril; 80/2015, de 30 de abril; 82/2015, de 30 de abril; 90/2015, de 11 de mayo; 91/2015, de 11 de mayo; 112/2015, de 8 de junio; 146/2015, de 6 de julio; 150/2015, de 6 de julio; 177/2015, de 22 de julio; 179/2015, de 7 de septiembre; 183/2015, de 10 de septiembre; 187/2015, de 21 de septiembre; 24/2016, de 15 de febrero, lo que supone un $14,7 \%$ de los casos admitidos a trámite.

91 De hecho, en la presentación de la Memoria 2014, el presidente del TC afirmó que a raíz de la STEDH Arribas Antón vs. España «la causa de la especial trascendencia constitucional de cada asunto admitido deberá expresarse en las providencias de admisión a trámite y la referencia a estas últimas se incluirá en los antecedentes de hecho de las sentencias». 
que le dan ocasión para aclarar o cambiar su doctrina [supuesto b) $]^{92}$, seguidos por los le que permiten interpretar nuevas facetas de derechos fundamentales donde no hay doctrina previa [supuesto a) $]^{93}$. Estos dos supuestos (Grundsatzannahme) suponen el 57,84 \% del total de recursos admitidos a trámite, en contraste con los supuestos para lograr la efectividad de los derechos fundamentales (Durchsetzungannhame), como el supuesto c ${ }^{94}$, el supuesto d ${ }^{95}$; supuesto e $)^{96}$; y supuesto $\left.\mathrm{f}\right)^{97}$, que suponen un $11,76 \%$; a lo que hay que añadir las admisiones basadas en la cláusula de cierre [supuesto g) $]^{98} \mathrm{o}$ varios supuestos en un mismo caso ${ }^{99}$ de los apuntados en la STC 155/2009, FJ 2.

92 SSTTCC 54/2015, de 16 de marzo, FJ 4; 65/2015, de 13 de abril; STC 74/2015, de 27 de abril; 87/2015, de 11 de mayo; 88/2015, de 11 de mayo; 96/2015, de 25 de mayo; 142/2015, de 22 de junio; 145/2015, de 25 de junio; 167/2015, de 20 de julio; 169/2015, de 20 de julio; 195/2015, de 21 de septiembre; 207/2015, de 5 de octubre; 208/2015, de 5 de octubre; 222/2015, de 2 de noviembre; 223/2015, de 2 de noviembre; 226/2015, de 2 de noviembre; 239/2015, de 30 de noviembre; 240/2015, de 30 de noviembre; 261/2015, de 14 de diciembre; 262/2015, de 14 de diciembre; 263/2015, de 14 de diciembre; 265/2015, de 14 de diciembre; 3/2016, de 18 de enero; $13 / 2016$, de 1 de febrero; $14 / 2016$, de 1 de febrero; 22/2016, de 15 de febrero; 34/2016, de 29 de febrero; 39/2016, de 3 de marzo; 49/2016, de 14 de marzo; 50/2016, de 14 de marzo; 103/2016, de 6 de junio; 117/2016, de 20 de junio; 136/2016, de 18 de julio; 137/2016, de 18 de julio.

93 SSTTCC 9/2015, de 2 de febrero, FJ 3); 19/2015, de 16 de febrero, FH 4; 24/2015, de 16 de febrero, FJ 2; 77/2015, de 27 de abril; 124/2015, de 8 de junio; 139/2015, de 22 de junio; 148/2015, de 6 de junio; 152/2015, de julio; 182/2015, de 7 de septiembre; 194/2015, de 21 de septiembre; 266/2015, de 14 de diciembre; 11/2016, de 1 de febrero; 12/2016, de 1 de febrero; 15/2016, de 1 de febrero; 16/2016, de 1 de febrero; 23/2016, de 15 de febrero; 44/2016, de 14 de marzo; 45/2016, de 14; 48/2016, de 14 de mayo; 64/2016, de 11 de abril; 65/2016, de 11 de abril; 69/2016, de 14 de abril; 83/2016, de 28 de abril; 112/2016, de 20 de junio; 132/2016, de 18 de julio.

94 STC 89/2015, de 11 de mayo.

95 Primera sentencia en la que el TC explicita este supuesto de admisión: STC 133/2016, de 18 de julio.

96 SSTTCC 42/2015, de 2 de marzo, FJ 2; 51/2016, de 14 de marzo; 92/2016, de 9 de mayo; 93/2016, de 9 de mayo; 98/2016, de 23 de mayo; 113/2016, de 20 de junio; 114/2016, de 20 de junio; 115/2016, de 20 de junio; 130/2016, de 18 de julio.

97 STC 138/2016, de 18 de julio.

98 SSTTCC 23/2015, de 16 de febrero, FJ 2; 10/2016, de 1 de febrero; 78/2016, de 25 de abril; 91/2016, de 9 de mayo.

99 SSTTCC 63/2016, de 11 de abril; 75/2016, de 25 de abril; 76/2016, de 25 de abril; 77/2016, de 25 de abril; 89/2016, de 9 de mayo; 94/2016, de 9 de mayo; 105/2016, 
Esta información es muy útil tanto para configurar un concepto más exacto y depurado de la especial trascendencia constitucional del recurso de amparo - y cumplir así mejor con su función objetiva - como para la preparación de futuros recursos y, por tanto, contribuir a la eficacia de su función subjetiva, contando con un escenario en el que la seguridad jurídica está completamente asegurada, tras ser puesta en tela de juicio por el TEDH. El TC vuelve a actuar conforme a los estándares europeos de máximo respeto a la buena administración de justicia, aunque para ello se haya puesto de manifiesto que, en materia de derechos fundamentales, "Constitucional no hay más que uno, pero no es el verdadero...»

\section{Bibliografía}

Aragón Reyes, M. (2009). La reforma de la Ley Orgánica del Tribunal Constitucional. Revista Española de Derecho Constitucional (85), 11-43.

Balaguer Callejón, F., Cámara Villar, G. y Medina Rey, L. F. (2008). La nueva Ley Orgánica del Tribunal Constitucional. Madrid: Tecnos.

Bustos Gisbert, R. (1999). ¿Está agotado el modelo de recurso de amparo diseñado en la Constitución Española? Teoría y Realidad Constitucional (4), 273-292.

Cabañas García, J. C. (2010). El recurso de amparo que queremos (reflexiones a propósito de la Ley Orgánica 6/2007, de 24 de mayo, de reforma parcial de la Ley Orgánica del Tribunal Constitucional). Revista Española de Derecho Constitucional (88), 39-81.

- El trámite de admisión del recurso de amparo y su especial trascendencia constitucional. En A. Montoya Melgar. Cuestiones actuales de la jurisdicción en España (pp. 253-273). Madrid: Dykinson.

Carrillo López, M. (2008). Hacia una nueva jurisdicción constitucional. Estudios sobre la Ley 6/2007 de 24 de mayo, de reforma de la LOTC. Valencia: Tirant lo Blanch.

Espín Templado, E., Fernández Farreres, G. y Cruz Villalón, P. (2006). La reforma de la justicia constitucional. Navarra: Centro de Estudios Jurídicos. Thomson Aranzadi.

Esquivel Alonso, Y. (2013). El requisito de la especial trascendencia constitucional: «decidir no decidir». Estudios de Deusto, 61 (2), 173-200. Disponible en: http://dx.doi.org/10.18543/ ed-61(2)-2013pp173-200.

Fernández Farreres, G. (2007). La reforma de la Ley Orgánica del Tribunal Constitucional. Revista Española de Derecho Constitucional (81), 11-62.

Garberí Llobregar, J. (2009). Réquiem por el recurso de amparo constitucional. Diario La Ley, 7088 y 7120.

González Alonso, A. (2013). ¿Ha cambiado algo el recurso de amparo español tras la aprobación de la LO 6/2007, de 24 de mayo? Justicia Administrativa. Revista de Derecho Administrativo (58), 17-40.

de 6 de junio; 107/2016, de 7 de junio; 108/2016, de 7 de junio; 109/2016, de 7 de junio; 129/2016, de 18 de julio; 131/2016, de 18 de julio. 
- y Ruiz-Risueño Montoya, F. (2015). El nuevo recurso de amparo constitucional a la luz del Convenio Europeo de Derechos Humanos (A propósito de la reciente sentencia del TEDH Arribas Antón c. España). Revista Española de Derecho Europeo (54), 155-183.

González Beilfuss, M. (2016). La especial trascendencia constitucional de las demandas de amparo. Análisis de la doctrina del Tribunal Constitucional sobre un concepto etéreo. Revista Española de Derecho Constitucional, 107, 333-367. Disponible en: http://dx.doi. org/10.18042/cepc/redc.107.10.

Hernández Ramos, M. (2008). Propuesta de desarrollo del nuevo trámite de admisión del recurso de amparo. Aspectos materiales y procedimentales. Revista de las Cortes Generales, 73, 31-66.

- (2009). El nuevo trámite de admisión del recurso de amparo constitucional. Madrid: REUS.

- (2011). La especial trascendencia constitucional del recurso de amparo y su aplicación en la jurisprudencia del Tribunal Constitucional. Luces y sombras de cuatro años de actividad. Revista Aranzadi Doctrinal (3), 101-112.

Matia Portilla, F. J. (2009). La especial trascendencia constitucional y la inadmisión del recurso de amparo. Revista Española de Derecho Constitucional (86), 343-368.

Morales Arroyo, J. M. (2014). El recurso de amparo, derechos fundamentales y trascendencia constitucional. El camino hacia la objetivación del amparo constitucional en España. Madrid: Thomson Reuters Aranzadi.

Ortega Gutiérrez, D. (2010). La especial trascendencia constitucional como concepto jurídico indeterminado. De la reforma de 2007 de la LOTC a la STC 155/2009, de 25 de junio. Teoría y Realidad Constitucional (25), 497-513.

Páez Mañá, J. (2012). El requisito de la especial trascendencia constitucional en los recursos de amparo interpuestos ante el tribunal constitucional español. En M. Bauzá Reilly. El derecho en la sociedad telemática: estudios en homenaje a Valentín Carrascosa López (pp. 511-543). Santiago de Compostela: Andavira.

Pérez Gurrea, R. (2012). El trámite de admisión del recurso de amparo: la especial trascendencia constitucional, Revista General de Derecho Procesal, 27, 5.

Pérez Tremps, P. (1994). La naturaleza del recurso de amparo y su configuración procesal. Revista Vasca de Administración Pública, 39, 89-103.

- (2008). La reforma del Tribunal Constitucional. Valencia: Tirant lo Blanch.

- (2015). El recurso de amparo, Valencia: Tirant lo Blanch.

Rodríguez-Piñeiro y Bravo Ferrer, M. (2015). La inadmisión del recurso de amparo y el Convenio Europeo de Derechos Humanos. Diario La Ley, 8503.

Sánchez de Ocaña Chamorro, R. (2013). La especial trascendencia constitucional del recurso de amparo en la doctrina del Tribunal Constitucional. Revista Aranzadi Doctrinal (6), 129-142.

Sánchez Morón, M. (1987). El recurso de amparo constitucional. Naturaleza jurídica, características actuales y crisis. Madrid: Centro de Estudios Constitucionales.

Tirado Estrada, J. J. (2012). Requisito particular de admisión del recurso: la especial trascendencia constitucional, Diario La Ley, 7838.

Urías Martínez, J. (2014). Seleccionar lo (menos) importante. Nota sobre la construcción por el Tribunal Constitucional de un nuevo régimen de admisibilidad del recurso de amparo, y sus paradojas. En J. M. Morales Arroyo. El recurso de amparo, derechos fundamen- 
tales y trascendencia constitucional. El camino hacia la objetivación del amparo constitucional en España (pp. 73-94). Madrid: Thomson Reuters Aranzadi.

VV.AA. (1999). Cuestionario sobre la reforma de la Ley Orgánica del Tribunal Constitucional. Teoría y Realidad Constitucional (4), 13-89. 
